\title{
Alcohol and blood pressure: a social comparison in Zimbabwe
}

\author{
Peter G. Bursztyn
}

Department of Physiology, Godfrey Huggins School of Medicine, University of Zimbabwe, Harare, Zimbabwe.

\begin{abstract}
Summary: The blood pressures of 252 men and 250 women, living in both urban and rural Zimbabwe, were measured on three separate occasions. Food and alcohol intakes were determined using a 3-day weighed diet survey checked by means of a detailed interview. Anthropometric data were also collected.

No relationship was found between mean blood pressures and the alcohol intake for any socioeconomic group. Using only the first of the three blood pressure measurements, a correlation between systolic pressure and alcohol intake was found for white males $(r=0.234, P<0.05)$, and just missed statistical significance $(r=0.156, P=0.065)$ for black middle class males. No relationship was found between blood pressure and alcohol consumption for black working class males, or for females.

Epidemiological evidence suggests that alcohol consumption is associated with increased blood pressure. However, a convincing physiological mechanism is lacking. It is suggested that psychological factors may be partly responsible for this relationship.
\end{abstract}

\section{Introduction}

Blood pressures increase with habitual alcohol intake in men and women (Klatsky et al., 1977; Harburg et al., 1980; Criqui et al., 1981; Arkwright et al., 1982a), although one older study saw no difference between drinkers and non-drinkers (Edwards et al., 1959). Saunders et al. (1981) showed that the blood pressures of heavy drinkers fall after a period of abstinence in hospital. Pretreatment blood pressures correlated well with both patients' alcohol consumption, and with the severity of their withdrawal symptoms. Potter \& Beevers (1984), controlling for the effects of hospitalization, demonstrated that alcohol withdrawal was itself responsible for decreasing the blood pressures of hypertensive patients.

The shape and magnitude of the relationship between blood pressure and alcohol is uncertain. Some studies demonstrate a good linear relationship with systolic, some with diastolic pressure, while others find poor correlations. McQueen \& Celentano (1982) proposed a ' $J$ ' shaped relationship, with modest drinkers having lower blood pressures than non-drinkers, and heavy drinkers showing the expected higher values.

Data published by Klatsky et al. (1977) show racial differences in the response of blood pressure to alcohol intake, with blacks exhibiting less sensitivity than whites. Also, McQueen \& Celentano (1982) argue that

Correspondence: P.G. Bursztyn, Ph.D. School of Biochemical and Physiological Sciences, University of Southampton, Southampton, SO9 3TU, UK.

Accepted: 17 June 1986 social factors may be important in the relationship between alcohol and blood pressure. The data obtained during a diet and blood pressure survey in Zimbabwe were used to analyse and compare the relationship between blood pressure and alcohol intake in whites and blacks in various socioeconomic groups.

\section{Methods}

Volunteers over the age of 18 were recruited from both urban and rural Zimbabwe. In the capital, Harare, institutions and industrial premises (including: a bank, a library, a food processing factory, a construction company, a newspaper, a school, and the city market) were approached for permission to survey their employees. Participants were unselected apart from their positive response to an advertisement at their place of work. A number of visits were made to each place over 3-4 weeks until data collection was completed.

In rural areas community leaders were visited, informed of the purpose of the survey, and asked for assistance in securing participation. Allowing 5-10 days for news to spread, the author and a technician lodged in each village for one week collecting data. Volunteers were unselected apart from their positive response to oral advertisement. However, the local school was always approached as the main source of rural middle class people. None of the respondents designated as rural worked in an urban area and the 
locations visited lacked both mains water and electricity supplies.

Each subject was interviewed before blood pressure measurement. Assignment to either 'middle class' or 'working class' was based on this interview. Professional, managerial, and clerical staff as well as skilled craftsmen were middle class. Manual labourers, market vendors, and peasants were working class. Wives were classified with their husbands. All of the whites surveyed were middle class and urban. Towards the end of the survey, premises and locations were selected to increase the numbers of urban middle class people.

Subjects were weighed to the nearest $100 \mathrm{~g}$ (light clothing, no shoes) on a Seca 770 portable digital scale. This instrument was checked regularly against a beam balance and found to be accurate. Heights were measured to the nearest $\mathrm{cm}$ using a stadiometer. Skinfolds were taken at four sites using Harpenden calipers: biceps, triceps, subscapular, and suprailiac, with three pinches at each site. Tables by Durnin \& Womersley (1974) were used to convert skinfold measurements into percentage body fat.

A 3-day weighed diet survey was carried out. Some individuals were unable to complete this, and some returned inaccurate data, leaving a total of 502 reliable records from the 737 people originally approached. Full details of this diet survey have been published (Bursztyn, 1985).

Drinking habits were assessed at interview on a 3 point scale $(>4$ times/week; $<4$ times/week; seldom or never) and checked against alcohol intakes recorded during the diet survey.

Alcohol intakes of problem drinkers are often underreported (Orrego et al., 1979). However, reproducible and reliable alcohol consumptions can be obtained from the general population (Williams et al., 1985). The diet survey instructions only mentioned alcohol with other beverages as a source of energy to be recorded and should not have triggered any anxiety regarding admission of alcohol intake.

Blood pressures were measured with two Hawksley Random-zero sphygmomanometers taking Korotkoff Phase V as the diastolic pressure. A standard cuff (balloon $130 \times 230 \mathrm{~mm}$ ) was used for most measurements. A large $(180 \times 360 \mathrm{~mm})$ and a small $(105 \times 190 \mathrm{~mm})$ cuff were available for use as required. Subjects were comfortably seated in a chair with armrests. All had been inactive for 10 minutes before measurement. Each measurement was the mean of 5 cuff inflations taken over 10 minutes. Three such measurements were recorded for all subjects on separate days. In urban areas, the 3 measurements were completed within 3 weeks; in rural areas, within one week. All the data were recorded by the author and one technician.

Blood pressure measurements were averaged for each subject. The mean value tabulated was the average of the three days' measurements. Correlations of blood pressure with alcohol consumption used this mean value, and were then repeated using the first measurement alone. Statistical manipulations were carried out using SPSS.

\section{Results}

Alcohol consumption recorded during the diet survey correlated well with the subjects' drinking habits as determined at interview. Subjects who claimed to be infrequent drinkers rarely recorded any alcohol intake during the survey period, while those who drank on 4 or more occasions each week all consumed more than $40 \mathrm{~g} /$ day of alcohol.

The table divided subjects by socioeconomic groups and by alcohol intake. Men were divided at an intake of $40 \mathrm{~g} /$ day and women at $10 \mathrm{~g} /$ day. Within groups, alcohol intakes and numbers of drinkers were higher among males. This difference was greatest for the middle class blacks and least for middle class whites. Black middle class males drank more and had a higher proportion of drinkers than the other groups. Among females, middle class whites drank most and had the highest proportion of drinkers. Few black females drank.

Male heavy and moderate drinkers were well mat ched for age, weight, Quetelet Index and percentage of body fat (Table I). The match was less good foI females (white moderate drinkers were younger than heavier drinkers). The small number of drinkers probably renders comparisons among black females inappropriate.

Energy intakes were higher among heavy drinkers. These differences are statistically significant for all male groups. The alcohol consumption of females was probably too small to affect total energy intakes.

Blood pressures were not related to drinking habits as reported at interview, nor did they differ significantly between high and low alcohol intake groups (Table I). The largest differences were seen among white males and females. For white females, the difference in systolic pressure disappeared on adjustment for age, for diastolic pressure the difference increased, but did not reach statistical significance. Age adjustment of black middle class blood pressures diminished the already small difference between high and low alcohol people.

The distribution of blood pressures in various groups were similar with respect to variance and skewness, suggesting that comparisons between groups are justifiable. Blood pressures tended to increase with age and with various measures of obesity. Again, differences between groups were small. These data are reported in full by Bursztyn \& Camp- 


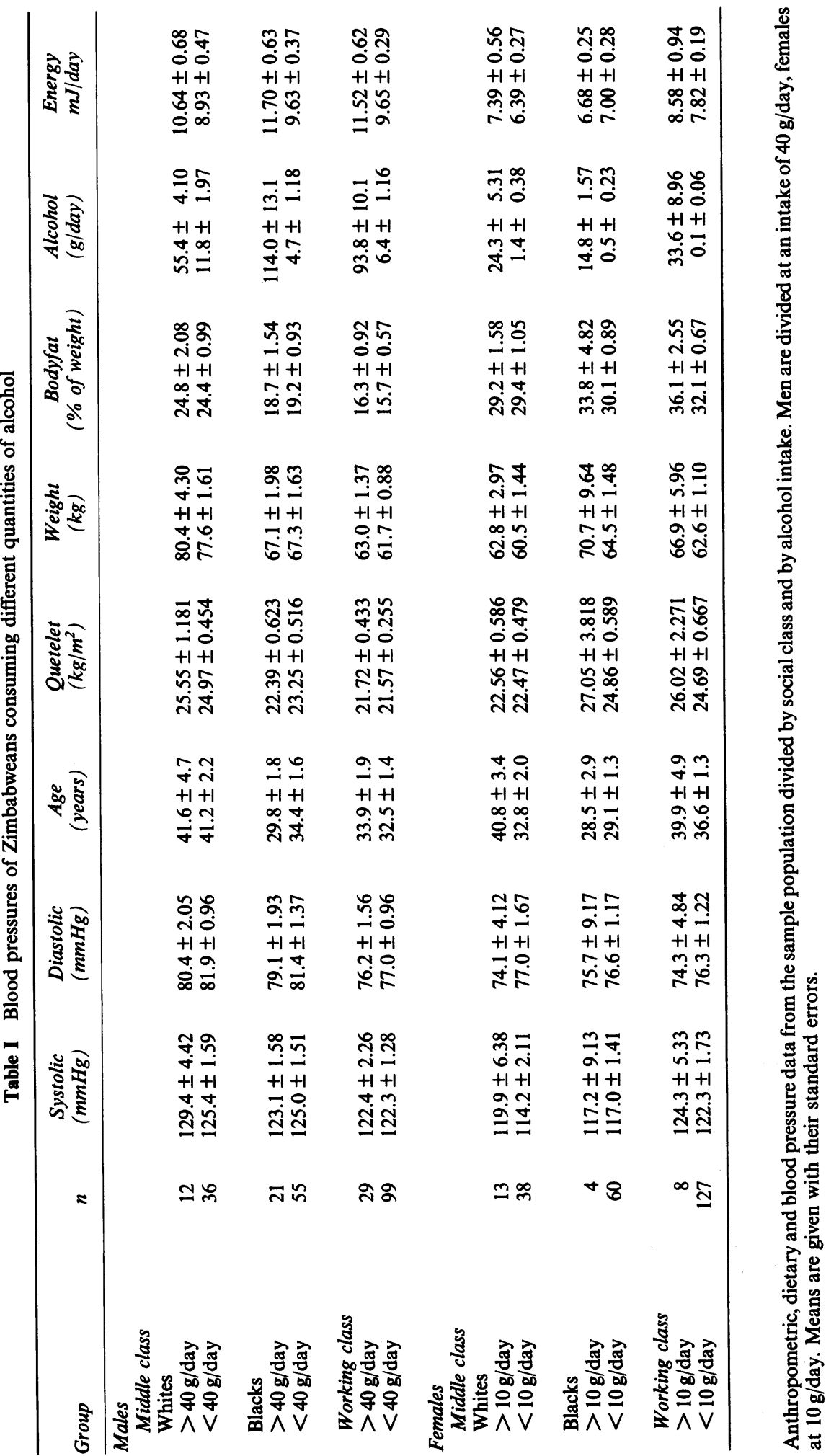


bell (in preparation).

Eight percent of the survey population were hypertensive (systolic $>160 \mathrm{mmHg}$, diastolic $>95 \mathrm{mmHg}$ ) or receiving treatment for hypertension. There is no suggestion that these individuals were predominantly drinkers. Deleting the data of 17 individuals who were under treatment for hypertension left tabulated values unchanged.

Multiple regression equations were constructed relating blood pressure to alcohol intake, age, weight, body fat and Quetelet Index. Only the partial regression coefficient between systolic pressure and alcohol intake for white males approached statistical significance $(r=0.176, P=0.065)$.

This analysis was repeated using only the blood pressure values obtained on the first measurement, instead of the mean values. Now the partial regression coefficient for systolic pressure and alcohol intake for white males attained statistical significance $(r=0.234$, $P<0.05$ ), and that for black middle class males nearly achieved it $(r=0.156, P=0.065)$.

The blood pressures of black working class males and of all female groups were unrelated to alcohol intake, regardless of whether the mean value or the first measurement were used in the analysis.

\section{Discussion}

The survey was, necessarily, restricted to volunteers who may not be typical of the population. However, drinkers did not differ physically from non-drinkers. Hypertension is symptomless (Gill \& Beevers, 1983) and participation would not have been influenced by blood pressure. This, and the observation that the distribution of blood pressure was similar in all groups suggests that comparisons between groups should be valid.

Although there is good epidemiological evidence that chronic alcohol consumption is associated with elevated blood pressure, few experimental studies have been able to demonstrate a pressor effect of ethanol. Chronic administration of large quantities of alcohol reduced blood pressures in rats (Maines \& Aldinger, 1967; Morvai \& Ungsvary, 1979), but left the blood pressures of dogs unchanged (Pachinger et al., 1973; Regan et al., 1974).

Puddey et al. (1985), gave normotensive volunteers either strong or weak beer for two periods of 6 weeks and showed that chronic alcohol consumption increased blood pressure modestly. On the other hand, Malhotra et al. (1985) found that 5 days of alcohol ingestion had no effect on normotensive blood pressures, although the blood pressures of a hypertensive group of volunteers were increased.

A recent longitudinal study (Kromhout et al., 1985) reported that blood pressures correlated with alcohol intake in each of three, 5-yearly surveys of a population of middle aged men. However, changes in alcohol intake correlated poorly with changes in blood pressure over the 10 years. This implies that blood pressure may be characteristic of the drinker, rather than his alcohol consumption.

In the present survey, the systolic pressures of white males were higher among heavier drinkers, but the difference was not statistically significant. A significant correlation between systolic pressure and alcohol intake was found among white males, but only based on the first measurement of blood pressure. Despite a greater intake of alcohol among black male drinkers, there were no differences in blood pressure between heavy and light drinkers in these groups. While a poor correlation between blood pressure and alcohol consumption was found among black middle class males, there was none at all among working class black males.

'Imprecise data will weaken correlations and underestimate regressions of blood pressure on associated variables' (Armitage et al., 1966). However, the present results show that the correlation between alcohol intake and systolic pressure improves using the first measurement instead of the more accurate mean value. Initial measurements of blood pressure are higher than subsequent measurements on the same individual and psychological factors are probabl 8 responsible for much of this decrease in pressure o remeasurement (Ostfeld \& Lebovits, 1960; Mawsok 1977; Bursztyn et al., 1981; Hartley et al., 1983). alcohol consumption affects the first measurement but not the mean, this implies that its effect is partly psychological.

The possibility of a psychological link between alcohol intake and blood pressure is reinforced by the observation that middle class whites are more affected than middle class blacks, and working class blacks not at all. Attitudes to alcohol consumption vary. Zimbabwean whites tended to be slightly apologetic about their alcohol consumption. Blacks (particularly the working class) were not; moreover, they gained in status through the use of spirits rather than beer, and lager beer rather than cheaper traditional millet beer.

Stress resulting from financial or family pressure might affect the blood pressures of low income drinkers. However, in Zimbabwe a rural or a working class woman would be less likely to complain about her husband's drinking habits than a middle class woman (Bourdillon, 1982). Moreover, some urban working class black men live apart from their (rural) families and are subject to even less family pressure.

Another group in whom no relationship between alcohol consumption and blood pressure could be found were 350 male recruits to the Australian armed forces (Baghurst \& Dwyer, 1981). Although the authors do not comment, one would expect this young 
population to have a casual attitude to alcohol.

Endocrinological factors have been identified which could be responsible for elevated blood pressures in heavy drinkers (Linkola et al., 1979; Bannan et al., 1984). However, no convincing mechanism has been advanced to explain the relationship between blood pressure and alcohol intake in modest drinkers (Howes \& Reid, 1986). Thus, Arkwright et al. (1982b), matching 30 pairs of male drinkers with non-drinkers, failed to find differences in circulating catecholamines, renal pressor hormones, or vascular reactivity, either at rest or under physiological stress.

It is suggested that psychological factors may be partly responsible for the observed relationship between alcohol consumption and blood pressure.

\section{References}

ARKWRIGHT, P.D., BEILIN, L.J., ROUSE, I., ARMSTRONG, B.K. \& VANDONGEN, R. (1982a). Effects of alcohol use and other aspects of lifestyle on blood pressure levels and prevalence of hypertension in a working population. Circulation, 66, 60.

ARKWRIGHT, P.D., BEILIN, L.J., VANDONGEN, R., ROUSE, I.A. \& LALOR, C. (1982b). The pressor effect of moderate alcohol consumption in man: a search for mechanisms. Circulation, 66, 515.

ARMITAGE, P., FOX, W., ROSE, G.A. \& TINKER, C.M. (1966). The variability of measurements of casual blood pressure: survey experience. Clinical Science, 30, 337.

BAGHURST, K.I. \& DWYER, T. (1981). Alcohol consumption and blood pressure in a group of young Australian males. Journal of Human Nutrition, 35, 257.

BANNAN, L.T., POTTER, J.F., BEEVERS, D.G., SAUNDERS, J.B., WALTERS, J.R.F. \& INGRAM, M.C. (1984). Effect of alcohol withdrawal on blood pressure, plasma renin activity, aldosterone, cortisol and dopamine $\beta$-hydroxylase. Clinical Science, 66, 659.

BOURDILlON, M.F. (1982). In The Shona Peoples, 2nd Ed. Mambo Press: Gweru, Zimbabwe.

BURSZTYN, P.G. (1985). A diet survey in Zimbabwe. Human Nutrition, 39A, 376.

O'DONOVAN, B. \& CHARLTON, I. (1981). Blood pressure variability: the effects of repeated measurement. Postgraduate Medical Journal, 57, 488.

CRIQUI, M.H., WALLACE, R.B., MISHKEL, M., BARRETTCONNOR, E. \& HEISS, G. (1981). Alcohol consumption and blood pressure. Hypertension, 3, 557.

DURNIN, J.V.G.A. \& WOMERSLEY, J. (1974). Body fat assessed from total body density and its estimation from skinfold thickness: measurements on 481 men and women aged 16 to 72 years. British Journal of Nutrition, 32, 77.

EDWARDS, F., McEOWN, T. \& WHITFIELD, A.G.W. (1959). Arterial pressure in men over sixty. Clinical Science, 18, 289.

GILL, J.S. \& BEEVERS, D.G. (1983). Hypertension and wellbeing. British Medical Journal, 287, 1490.

HARBURG, E., OZGOREN, F., HAWTHORNE, V.M. \& SCHORK, M.A. (1980). Community norms of alcohol usage and blood pressure: Tecumseh, Michigan. American Journal of Public Health, 70, 813.

\section{Acknowledgements}

I would like to thank Professor E.A. Petropoulos for his encouragement and for arranging my teaching schedule to facilitate this work. Mr Kenneth Ndoro's advice and technical assistance were invaluable. The project was funded by grants from the Sims Black Medical Foundation and the University of Zimbabwe Research Board. The work was carried out while the author was on leave from the University of Southampton.

HARTLEY, R.M., VELEZ, R., MORRIS, R.W., D'SOUZA, M.F. \& HELLER, R.F., (1983). Confirming the diagnosis of mild hypertension. British Medical Journal, 286, 287.

HOWES, L.G. \& REID, J.L. (1986). The effects of alcohol on local, neural and hormonal cardiovascular regulation. Clinical Science, 71, 9.

KLATSKY, A.L., FRIEDMAN, G.D., SIEGELAUB, A.B. \& GERARD, M.J. (1977). Alcohol consumption and blood pressure: Kaiser-Permanente multiphase health examination data. New England Journal of Medicine, 296, 1194.

KROMHOUT, D., BOSSCHIETER, E.B. \& COULANDER C.L. (1985). Potassium, calcium, alcohol intake and blood pressure: the Zutphen Study. American Journal of Clinical Nutrition, 41, 1299.

LINKOLA, J., FYHRQUIST, F. \& YLIKAHRI, R. (1979). Renin, aldosterone and cortisol during ethanol intoxication and hangover. Acta Physiologica Scandinavica, 106, 75.

MAINES, J.E. \& ALDINGER, E.E. (1967). Myocardial depression accompanying chronic consumption of alcohol. American Heart Journal, 73, 55.

MALHOTRA, H., MEHTA, S.R., MATHUR, D. \& KHANDELWAL, P.D. (1985). Pressor effects of alcohol in normotensive and hypertensive subjects. Lancet, ii, 584.

MAWSON, A.R. (1977). Hypertension, blood pressure variability, and juvenile delinquency. Southern Medical Journal, 70, 160.

MCQUEEN, D.V. \& CELENTANO, D.D. (1982). Social factors in the etiology of multiple outcomes: the case of blood pressure and alcohol consumption patterns. Social Science and Medicine, 16, 397.

MORVAI, V. \& UNGSVARY, G. (1979). Effect of chronic exposure to alcohol on the circulation of rats of different ages. Acta Physiologica, Academiae Scientiarum Hungaricae, 53, 433.

ORREGO, H., BLENDIS, L.M., BLAKE, J.E., KAPUR, B.M. \& ISRAEL, Y. (1979). Reliability of assessment of alcohol intake based on personal interviews in a liver clinic. Lancet, ii, 1354.

OSTFELD, A.M. \& LEBOVITS, B.Z. (1969). Blood pressure liability: a correlative study. Journal of Chronic Disease, $12,428$.

PACHINGER, O.M., TILLMANS, H., MAO, J.C., FAUVEL, J-M. \& BING, R.J. (1973). The effect of prolonged administration 
of ethanol on cardiac metabolism and performance in the dog. Journal of Clinical Investigation, 52, 2690.

POTTER, J.F. \& BEEVERS, D.G. (1984). Pressor effect of alcohol in hypertension. Lancet, $\mathbf{i}, 119$.

PUDDEY, I.B., BEILIN, L.J., VANDONGEN, R., ROUSE, I.L. \& ROGERS, P. (1985). Evidence for a direct effect of alcohol consumption on blood pressure in normotensive men. Hypertension, 7, 707.

REGAN, T.J., KHAN, M.I., ETTINGER, P.O., HAIDER, B.,
LYONS, M.M., OLDEWURTEL, H.A. \& WEBERM, M.ำ (1974). Myocardial function and lipid metabolism in the $\bar{Z}$

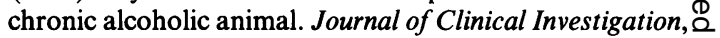
54, 740.

SAUNDERS, J.B., BEEVERS, D.G. \& PATON, A. (1981) Alcohol-induced hypertension. Lancet, ii, 653.

WILLIAMS, G.D., AITKEN, S.S. \& MALIN, H. (1985). Re-O liability of self-reported alcohol consumption in a general흐 population survey. Journal of Studies on Alcohol, 46, 223. $\frac{\overline{\bar{s}}}{\overline{\frac{\sigma}{\sigma}}}$ 